\title{
Characterization of Aircraft Wake Vortices by Airborne Coherent Doppler Lidar
}

\author{
Stephan Rahm, Igor Smalikho, and Friedrich Köpp \\ DLR, German Aerospace Center, 82234 Wessling, Germany
}

DOI: $\underline{10.2514 / 1.24401}$

\begin{abstract}
This paper presents a new method of wake-vortex characterization by using the $2-\mu \mathrm{m}$ coherent Doppler lidar in airborne configuration. After modification of the scanning and data acquisition tools, the lidar system has been integrated in the DLR research aircraft Falcon 20. For wake-vortex generation a second DLR aircraft, the Advanced Technologies Testing Aircraft System equipped with a smoke generator on the portside wing, was used. Different scanning modes and flight strategies have been investigated and tested during three tryout flights. Results of vortex trajectories and circulation strengths, measured in the upper part of and above the atmospheric boundary layer, are presented. Based on the results of the tryout flights, the potential of this method for characterization of wake vortices from large transport aircraft equipped with smoke generators is estimated.
\end{abstract}

\section{Introduction}

D URING several field experiments [1,2], the 2- $\mu \mathrm{m}$ Doppler lidar from DLR was used in ground-based configuration for characterization of wake vortices generated by large transport aircraft (LTA). The high quality of the lidar signatures allowed both the tracking of the vortices up to several minutes after aircraft flyby and the derivation of characteristic features, like core separation, wake tilting, and vortex circulation strength with high accuracy. From the promising experience of ground-based lidar measurements on smoke-seeded vortices during the aircraft wing with advanced technology operation (AWIATOR) flight test F/T-1 [3] , the idea was born to use the $2-\mu \mathrm{m}$ lidar onboard a second aircraft. The main advantages of using the pulsed lidar in airborne configuration for wake-vortex (WV) characterization are the following:

1) the possibility of long-lasting observations during several vortex phases, including the vortex decay phase,

2) the possibility of performing the measurements in a relatively undisturbed atmosphere with low turbulence level outside the ground effects,

3) the possibility of flight-test execution more or less independently of the prevailing crosswind,

4) the possibility of wake-vortex investigations even at cruise altitude.

The detection of wake vortices by airborne Doppler lidar has already been demonstrated [ㄴ,5], whereas their characterization by such a method was not realized yet. Therefore, it was necessary to estimate the expected system performance and to carry out careful tradeoffs with respect to available seeding time, length of "frozen" vortex section, spatial (angular) resolution, accuracy of tangential velocity, and so on. The results of these simulations are summarized in the feasibility study given in [6].

For experimental demonstration of the method by performing socalled tryout flights, the following items have to be taken into account:

1) The vortices are generated by an aircraft equipped with smoke generator(s), in such providing strong lidar signals (SNR $\geq 1$, where SNR is the ratio of the mean signal power to the mean noise power within the bandwidth of $50 \mathrm{MHz}$ ) which reduces the number of lidarshot accumulations needed to provide high angular (spatial) resolution [1].

Received 3 April 2006; revision received 27 June 2006; accepted for publication 3 July 2006. Copyright $\odot 2006$ by the American Institute of Aeronautics and Astronautics, Inc. All rights reserved. Copies of this paper may be made for personal or internal use, on condition that the copier pay the $\$ 10.00$ per-copy fee to the Copyright Clearance Center, Inc., 222 Rosewood Drive, Danvers, MA 01923; include the code 0021-8669/07 \$10.00 in correspondence with the CCC.
2) In view of the wake deformations due to Crow instabilities [7] and weather effects, a portion along the wake with a length of $\leq 10 \mathrm{~m}$ should be frozen. This can be achieved by appropriate adaptation of the scanning strategy.

3) Sufficient measurements should be taken to define the different vortex phases in a statistical way, for example, by a probability distribution of the vortex strength (circulation) at a particular downstream position. Thereby, the number of recorded realizations (one realization is a frozen vortex section) and the number of downstream positions are limited by the maximum smoke time per flight.

4) The aircraft with the lidar system onboard should fly $\sim 900 \mathrm{~m}$ above the wake-generating aircraft to have the descending vortex pair within the optimum range $(\sim 1000 \mathrm{~m})$ for high system performance, both with respect to lidar sensitivity and spatial resolution.

5) Weather forecast and monitoring is needed to fly both aircraft in homogeneous weather conditions (wind speed and direction, turbulence, thermal stratification).

\section{Aircraft and Lidar Equipment \\ Lidar Onboard Falcon 20 Aircraft}

For airborne wake-vortex characterization, the pulsed Doppler lidar integrated in the DLR research aircraft Falcon 20 was used. For this application, a more advanced scanning device, consisting of two counter-rotating prisms, and a new mounting frame have been developed. Moreover, the whole instrumentation had to be certified for airborne application within a few months. The main parameters of the lidar, as chosen for the tryout experiment, are listed in Table 1; the integration of transceiver and scanner units in the Falcon aircraft is shown in Fig. 1 .

From the backscatter signals measured by the lidar, the array of Doppler spectra at different ranges and scan angles is obtained using five shots (time interval between shots is $0.002 \mathrm{~s}$ ) for the spectral accumulation. Choosing the appropriate threshold, the envelopes of the along line-of-site velocity component (positive and negative) as a 2-D function of range and scan angle are derived from the Doppler spectra. From the velocity envelopes the vortex core coordinates and the vortex circulation are estimated. The procedure of data processing is described in detail in [1].

\section{Vortex-Generating Aircraft ATTAS}

For wake-vortex generation, the ATTAS (Advanced Technologies Testing Aircraft System) operated by DLR Braunschweig was used. It is a VFW 614 aircraft with 20 ton mass and $21.5 \mathrm{~m}$ span generating wake vortices with an initial circulation strength of $\Gamma_{0}$ of about $150 \mathrm{~m}^{2} / \mathrm{s}$. A smoke generator was mounted on the left wing of 
Table 1 Main parameters of the pulsed Doppler lidar

\begin{tabular}{lcc}
\hline \hline Laser system: & Transceiver MAG-1 from CTI (Coherent Technologies, Inc.) & $2022.54 \mathrm{~nm}$ \\
& wavelength (Tm:LuAG) & $2.0 \mathrm{~mJ}$ \\
& pulse energy & $400 \pm 40 \mathrm{~ns}$ \\
& pulse length (FWHM) & $500 \mathrm{~Hz}$ \\
& pulse repetition rate & $102 \pm 3 \mathrm{MHz}$ \\
& LO/SO (local/slave oscillator) frequency offset & $108 \mathrm{~mm}$ \\
Telescope: & Off-axis type aperture & $\pm 15 \mathrm{deg}$ \\
Scanner unit: & Two counter-rotating prisms & $3 \mathrm{~s}$ \\
& scan range & $>1 \mathrm{~s}$ \\
& scan duration & \\
Data acquisition: & turnback time & $500 \mathrm{MHz}$ \\
& Concept of early digitizing & $0.3 \mathrm{~m}$ \\
Measurement range: & sampling rate & $18 \mathrm{~m}$ \\
Doppler spectra sampling: & sample length & $1-3 \mathrm{~m}$ \\
\hline \hline
\end{tabular}

the ATTAS for seeding the portside vortex (Fig. 2), to visualize the position of the wake for wake tracking and to provide high backscatter values for efficient lidar measurements. The capacity of the smoke pod can generate smoke plumes of 12 min duration. This technique was already successfully tested in the C-Wake campaign [8] carried out in 2002.

\section{Strategy of Airborne Wake-Vortex Characterization} Scanning Strategy

The lidar system has been equipped with a scanning device allowing flexible beam deflection operation techniques with high angular (spatial) and temporal resolution. Several scan strategies were considered, with the two most promising treated as follows:

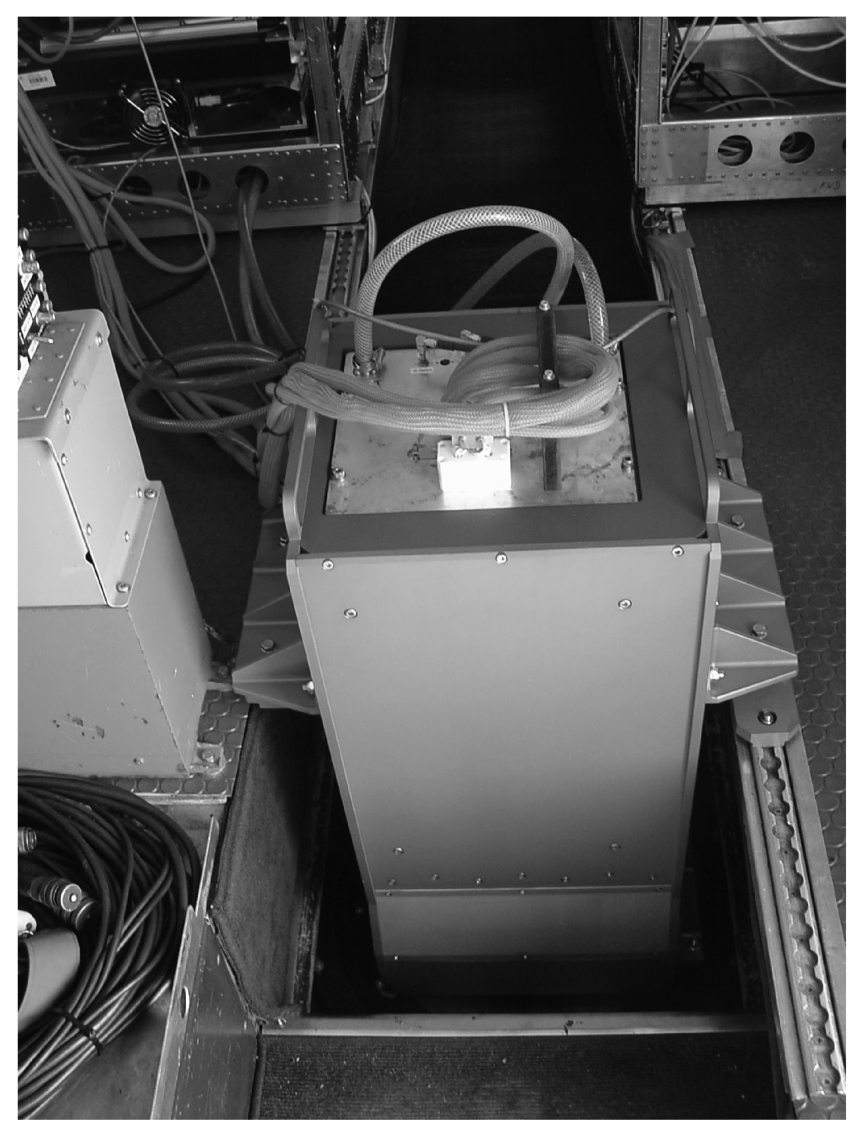

Fig. 1 Integration of laser transceiver and scanner units in the frame construction mounted above the cutout in the fuselage underside of the Falcon aircraft.
Linear scan perpendicular to flight direction: This is the usual scan procedure, resulting in a zigzag pattern defined by the speed of the airborne platform and the scan rate. Assuming a speed of, for example, $111 \mathrm{~m} / \mathrm{s}$ and a scan duration in one direction of $3 \mathrm{~s}$, the longitudinal extension along the flight direction becomes $333 \mathrm{~m}$ for a single scan. Choosing a scan angle of $\pm 15 \mathrm{deg}$ to both sides of the nadir direction, the extension perpendicular to the flight direction, the so-called swath, is $\pm 267 \mathrm{~m}$ for a mean measurement range of $1000 \mathrm{~m}$. The diameter of a single vortex can be defined by the outer integration boundaries, which are, for example, in the case of wake vortices generated by LTA, $15 \mathrm{~m}$ around the vortex core. Under this assumption, a single vortex covers a fraction of $(2 \times 15 \mathrm{~m}) /(2 \times$ $267 \mathrm{~m}$ ) of the 3 -s scanning time. In this time period of roughly $0.17 \mathrm{~s}$ the aircraft flies a distance of $18.7 \mathrm{~m}$, and therefore, the longitudinal extension of a single vortex section becomes $\sim 19 \mathrm{~m}$. That means the measured data are not representing a frozen vortex section, and hence, a more sophisticated scan procedure is required.

Linear scan with lead angle: In this configuration, the scanning plane is turned around the vertical axis $Z$ by an angle compensating the forward motion caused by the aircraft flight speed $V_{a}$. This socalled lead angle $\theta$ has to be adapted to the speed of the airborne platform and to the height difference $\Delta h$, that is, the difference of the heights of the lidar and the plane of wake-vortex observation. It can be defined from the equations for the horizontal coordinates $\{x, y\}$ of the point, where the probing beam intersects the horizontal plane at the height of vortex observation:

$$
\begin{gathered}
x(t)=\Delta h \cdot \cos \theta \cdot \tan \left(\omega t^{\prime}\right) \\
y(t)=V_{a} t^{\prime}-\Delta h \cdot \sin \theta \cdot \tan \left(\omega t^{\prime}\right)
\end{gathered}
$$

where $x$ is the transversal coordinate (perpendicular to the flight

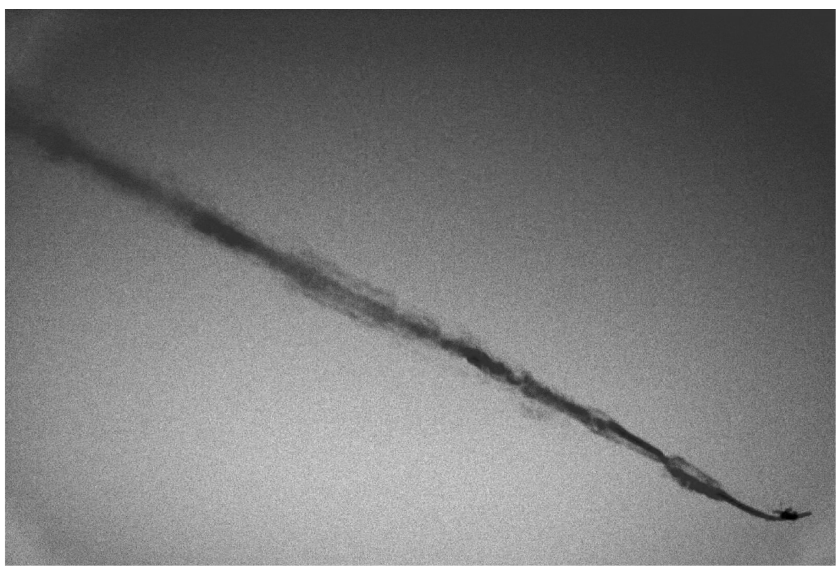

Fig. 2 ATTAS aircraft with smoke-seeded port vortex. 


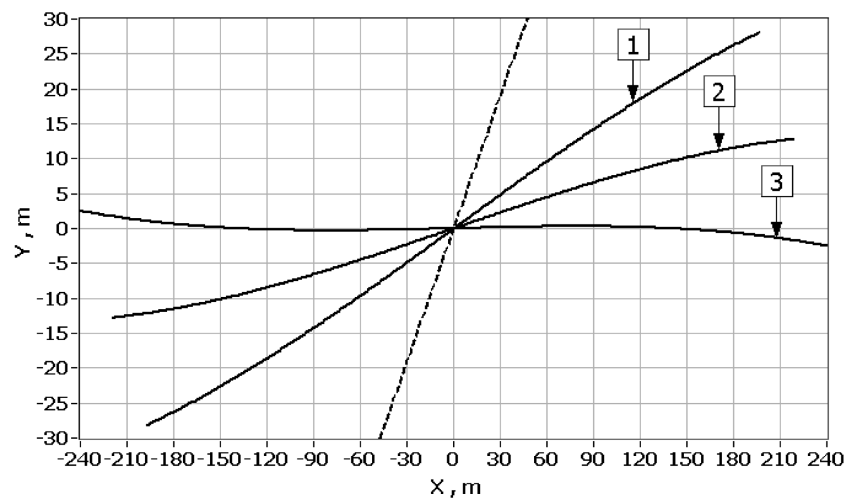

Fig. 3 Shape of the lidar beam intersections with horizontal planes at $900 \mathrm{~m}(1), 1000 \mathrm{~m}(2)$, and $1100 \mathrm{~m}(3)$ below the Falcon aircraft. The solid curves $1,2,3$ and the dashed curve $(\Delta h=1000 \mathrm{~m})$ show the calculation results for lead angles of 35 and $0 \mathrm{deg}$, respectively.

direction), $y$ is the longitudinal coordinate (along the flight direction), $t$ is the time within a single scan $\left(t \in\left[0, t_{s}\right], t_{s}=3 \mathrm{~s}\right.$ is the duration of a single scan), $t^{\prime}=t-t_{s} / 2, \omega=2 \pi / T$ is the angular speed of scanning, and $T=36 \mathrm{~s}$. Taking into account that $-15 \leq \omega t^{\prime} \leq 15 \mathrm{deg}$, the approximation $\tan \left(\omega t^{\prime}\right) \approx \omega t^{\prime}$ can be used in Eq. (2) and when requiring $y(t)=0$ the approximate formula for the lead angle $\theta$ becomes

$$
\theta=\arcsin \left(\frac{V_{a}}{\omega \cdot \Delta h}\right)
$$

In this way, the forward motion (due to the aircraft flight) of the point of intersection of the laser beam with the horizontal plane can be completely compensated for the height difference $\Delta h$. This compensation $[y(t) \approx 0]$ is most important for old wake vortices, when random variations (due to turbulence) of the $X$ component of the vortex core position along the $Y$ axis can be essential for vortex characterization. We assume that in our experiment the initial height difference $\Delta h=900 \mathrm{~m}$. Because of the vortex descent $\Delta h$ can increase up to more than $1100 \mathrm{~m}$ (even more for large aircraft, because sink distance scales with wing span), when the vortices are becoming older. Using $V_{a}=111 \mathrm{~m} / \mathrm{s}$ and $\Delta h=1100 \mathrm{~m}$ in Eq. (3), we obtain for these conditions the optimal lead angle $\theta \approx 35 \mathrm{deg}$.

The tracks of the scanning lidar beam [calculated by Eqs. (1) and (2)], as the intersection of the scanning beam with the horizontal measurement planes at distances of $900 \mathrm{~m} \mathrm{(1),} 1000 \mathrm{~m} \mathrm{(2),} \mathrm{and}$ $1100 \mathrm{~m} \mathrm{(3)} \mathrm{below} \mathrm{the} \mathrm{airborne} \mathrm{lidar,} \mathrm{are} \mathrm{sketched} \mathrm{by} \mathrm{the} \mathrm{solid} \mathrm{lines} \mathrm{in}$ Fig. 3. In this example, the lead angle is $35 \mathrm{deg}$, the scan angle is $\pm 15^{-}$deg now covering a smaller swath of, for example, $\pm 220 \mathrm{~m}$ at $1000 \mathrm{~m}$ height difference (due to $35 \mathrm{deg}$ turning of the scan plane), and the scan duration is $3 \mathrm{~s}$ for a single scan, for example, from left to right. In the case of $\Delta h=1000 \mathrm{~m}$, for example, the longitudinal extension of a single vortex section $x$ is always less than $2 \mathrm{~m}$, and hence, the requirement of measuring on a frozen vortex is fully met.

Several programs for scanner control (slow/fast speed, with/ without lead angle) have been prepared. They can be started and changed during the measurement flights.

\section{Flight Strategy}

The success of the airborne wake-vortex characterization strongly depends on the selection of flight pattern and speed of both aircraft. Two strategies have been considered with respect to the optimal use of the available smoke (12 min for ATTAS), the minimum flight duration and the minimum risk of losing the wake vortex. For both strategies, it is assumed that the flight patterns are aligned with the prevailing wind direction to minimize the influence of crosswind components. The speed of both aircraft must be high enough to allow stable flight conditions above the atmospheric boundary layer (ABL), for example, at $2000 \mathrm{~m}$ above ground level (AGL), respectively, $2.900 \mathrm{~m}$ AGL. On the other hand, they should be as low

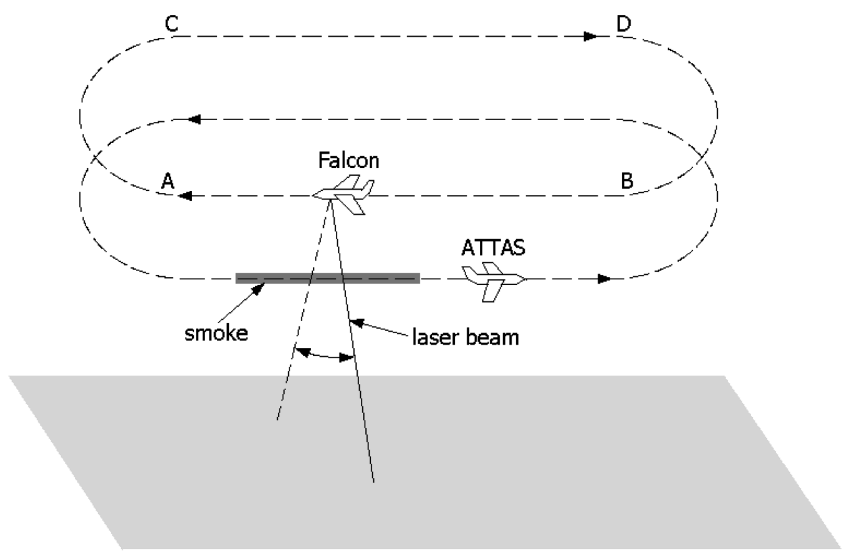

Fig. 4 Sketch of the idealized pattern to be flown both by the Falcon (clockwise) and the ATTAS aircraft (counterclockwise).

as possible to minimize the lead angle $\theta$ which is increasing with increasing aircraft speed $V_{a}$ [see Eq. (3)].

Chase pattern: Both aircraft are flying in the same direction on straight flight legs. There are different possibilities of choosing the aircraft speeds:

1) Both aircraft have similar speeds. The disadvantage of this solution is the time loss during position changes of the lidar platform by full circuits or meandering for heading the next measurement position.

2) The speed of the lidar platform is smaller than the ATTAS speed. In this case, the measurements are starting at the position of the vortex-generating aircraft and are continued during falling back of the lidar platform. Therefore, the risk of losing the vortices is small.

3) The speed of the lidar platform is higher than the ATTAS speed. This solution requires larger lead angles of $>45 \mathrm{deg}$. Moreover, it makes the wake-vortex tracking more difficult, because the measurements are starting at old vortex sections which may be difficult to find.

Circuit pattern: Both aircraft are flying in opposite directions on an oval pattern, as sketched in Fig. 4. It is a locally fixed pattern consisting of two straight sections of $10-20 \mathrm{~km}$ length connected by semicircles of several kilometer radius. After each turn, the aircraft have the possibility to adjust their flight direction on the straight section. Then the vortex-generating ATTAS releases a smoke plume of 1-2 min duration (indicated by the gray bar). It is envisaged that the lidar platform coming from the other end of the straight leg passes over the ATTAS in the moment when the smoke generator is switched off. Then, the plume of $5-10 \mathrm{~km}$ length is measured by the airborne lidar during flying over the plume in the opposite direction. In this way, 10 plume overflights can be carried out within five oval flight patterns, for example. A successful operation of this strategy requires continuous communication between both aircraft.

\section{Airborne Wake-Vortex Characterization}

The performance of the modified lidar system installed in the Falcon aircraft has been demonstrated during a workshop flight on 18 April 2005. After that, three tryout flights have been carried out in the South-Bavarian region.

1) Flight 1: 21.04.05, 09:05-09:56 UTC (universal time coordinated) and Flight 2: 21.04.05, 13:30-14:15 UTC:

The first two flights were partly successful due to cloud presence between the flight altitudes of ATTAS [(flight level) FL 45] and Falcon (FL 75).

2) Flight 3: 22.04.05, 07:56-09:10 UTC:

On the next day, the full circuit pattern could be flown (ATTAS at FL 55, Falcon at FL 85) under clear weather conditions with moderate north-westerly wind $\left(315^{\circ}\right)$. During five circuits, vortex signatures were measured on 10 straight flight legs. 
Table 2 Distribution of the total smoke of $\sim 12 \mathrm{~min}$ duration and the applied scan strategy for the 10 legs of flight 3

\begin{tabular}{|c|c|c|c|c|c|c|c|}
\hline \multicolumn{2}{|c|}{ Flight pattern } & \multicolumn{3}{|c|}{ Smoke generator } & \multicolumn{3}{|c|}{ Scan procedure } \\
\hline Leg no. & Section- & $\mathrm{ON}$ & OFF & Duration & Angle & Duration & Lead \\
\hline 1 & C-D & $08: 15: 55$ & $08: 16: 55$ & 1:00 & $\pm 25 \mathrm{deg}$ & $10 \mathrm{~s}$ & No \\
\hline $2^{\underline{b}}$ & A-B & $08: 20: 50$ & $08: 21: 50$ & 1:00 & $\begin{array}{l} \pm 25 \mathrm{deg} \\
\pm 15 \mathrm{deg}\end{array}$ & $\begin{array}{c}5 s \\
3+(3) s\end{array}$ & $\begin{array}{c}\text { No } \\
35 \mathrm{deg}\end{array}$ \\
\hline 3 & C-D & $08: 25: 35$ & $08: 26: 45$ & $1: 10$ & $\pm 15 \mathrm{deg}$ & $3+(3) s$ & $35 \mathrm{deg}$ \\
\hline 4 & A-B & $08: 30: 42$ & $08: 31: 22$ & $0: 40$ & $\pm 15 \mathrm{deg}$ & $3+(3) s$ & $35 \mathrm{deg}$ \\
\hline 5 & C-D & $08: 35: 25$ & $08: 36: 35$ & $1: 10$ & $\pm 15 \mathrm{deg}$ & $3+(3) \mathrm{s}$ & $35 \mathrm{deg}$ \\
\hline 9 & C-D & $08: 54: 45$ & $08: 56: 25$ & $1: 40$ & $\pm 15 \mathrm{deg}$ & $3+(3) s$ & $35 \mathrm{deg}$ \\
\hline 10 & A-B & 09:00:10 & 09:01:20 & $1: 10$ & $\pm 15 \mathrm{deg}$ & $3+(3) s$ & $35 \mathrm{deg}$ \\
\hline
\end{tabular}

${ }^{\mathrm{a} A s}$ sketched in Fig. $4 . \quad{ }^{\mathrm{b}}$ Test of scan change between scans 2 and 3.

\section{Tryout Flight No. 3}

Flight 3 (22.04.05, 07:56-09:10 UTC) was carried out in a clear and quiet atmosphere, characterized by high visibility (estimated $>100 \mathrm{~km}$ ) in the height level of the experiment (1500$2500 \mathrm{~m}$ AGL).

It was envisaged to fly 5 times the pattern sketched in Fig. 4, consisting of five oval loops, respectively, 10 straight flight legs. The flight duration for one loop was approximately $10 \mathrm{~min}$. The wakegenerating ATTAS flew at FL 55 with a true air speed (TAS) of $67 \mathrm{~m} / \mathrm{s}$, the lidar-platform Falcon at FL 85 with a TAS of $105 \mathrm{~m} / \mathrm{s}$ in the opposite direction (counterclockwise). The ATTAS approach could be observed from the Falcon cockpit, the released smoke
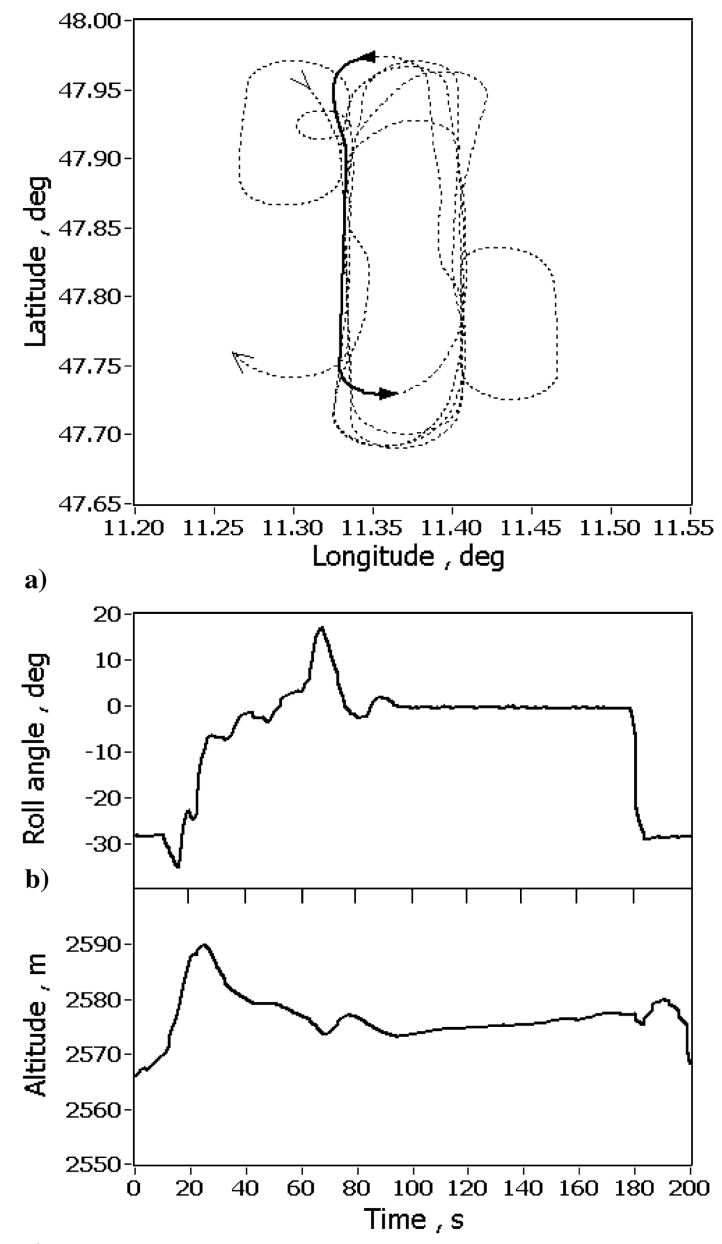

c)

Fig. 5 Course plot of the pattern flown by the Falcon during flight 3 a) with the first part of leg 2 drawn by the solid line. Aircraft attitude plotted for this part of leg 2: roll angle b), and flight altitude c). plume as well from the Falcon cockpit as through the floor window of the aircraft. As soon as the Falcon has passed over the ATTAS, the smoke has been switched off. For the 10 straight flight legs, the distribution of total smoke of $\sim 12$ min duration and the applied scan strategy are listed in Table 2.

The course flown by the Falcon is plotted in Fig. 5a. It consists of five large oval loops and several smaller loops used for adjustment to the ATTAS course. A closer look, for example, on the first part of $\operatorname{leg} 2$, is drawn by the full line. The period of course finding in the first part of this leg is followed by an extended straight section. The Falcon attitude on this leg is plotted in Figs. $\underline{5 b}$ and $\underline{5 c}$. After the period of course alignment, it shows very stable flight conditions both in roll angle $5 \mathrm{~b}$ and in flight altitude $5 \mathrm{c}$. The real wake-vortex measurement occurred in the period $11 \overline{5}-175 \mathrm{~s}$. Here is some potential for saving flight time in future campaigns.

\section{Wake-Vortex Signatures Measured on Flight No. 3}

During flight no. 3 , the scan methods without and with lead angle were tested. For leg 1, the method of zigzag scanning was chosen. Thereby, a nadir angle of $\pm 25 \mathrm{deg}$ was scanned within $10 \mathrm{~s}$; no lead angle was applied. Figure $\underline{6}$ shows the velocity envelopes at the range equal to the distance between lidar and vortex region and the nadir angle versus the number of line-of-site (LOS) measurements. Here one can see the wake-vortex signatures measured by the lidar during two scans. Because of the accumulation of five shots, we find pronounced signatures of the smoke-seeded port vortex; the unseeded one is weakly perceptible. The vortices were first detected at the left edge of the scan sector near $-18 \mathrm{deg}$. The second scan intersection $\sim 1 \mathrm{~s}$ later has already moved to $-21 \mathrm{deg}$ and the next scan $\sim 18 \mathrm{~s}$ later did not show any vortex signatures. The wake vortices were lost after two scans, probably due to the relative small scan speed and a nonoptimal adjustment of the flight direction. In this case of measuring without lead angle, the signature of one vortex is spread over $\sim 2.5 \mathrm{deg}$ which is scanned within $\sim 0.5 \mathrm{~s}$. That means, the measurement covers a longitudinal section of one single vortex of

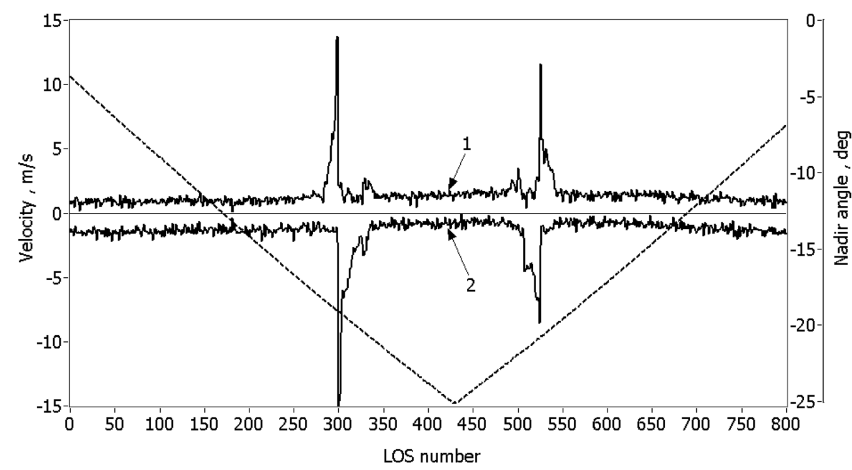

Fig. 6 Lidar signatures of the wake-vortex pair measured during two scans. The solid curves are representing the positive (1) and negative (2) velocity envelope; the dashed curve shows the slope of the nadir angle. 


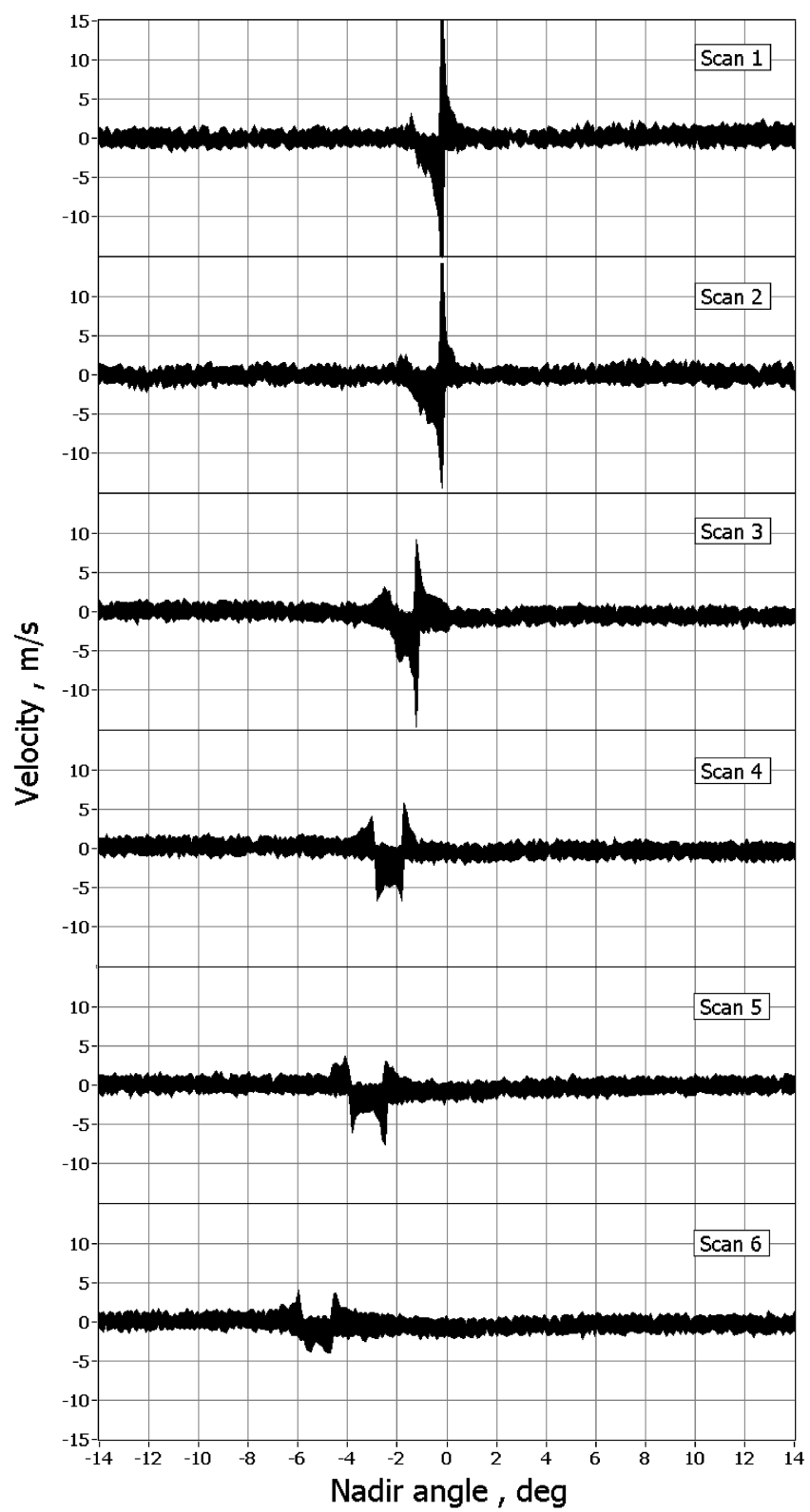

Fig. 7 Lidar signatures (positive and negative envelopes) of the ATTAS vortex pair measured during six scans on leg 2 of flight no. 3 .

$\sim 50 \mathrm{~m}$. This may be accepted for young well-developed ATTAS vortices, but not for older, sometimes meandering vortices [7].

For the first two scans of leg 2, the scan angle was \pm 25 deg and the scan time was $5 \mathrm{~s}$, in which no lead angle was applied. The measured vortex signatures, as the positive and negative velocity envelopes, are now plotted with filled areas between the corresponding curves in Fig. 7.

Between scans 2 and 3, the scanning was changed to the method with lead angle of $35 \mathrm{deg}$ with simultaneous reduction of the scan angle to $\pm 15 \mathrm{deg}$ and the scan time to $3 \mathrm{~s}$ plus $3 \mathrm{~s}$ for turnback of the scanner prisms. In this way, the possibility of combining two scanning strategies during one sequence of measurements could be demonstrated. The measured vortex signatures of scans 3-6 are plotted in the lower part of Fig. 7, showing the decrease of the vortex strength. Moreover, an interesting feature can be observed, namely, the transport of smoke particles from the seeded port vortex to the originally unseeded starboard vortex after approximately 3-4 scans. Because of the optimized lead angle of $35 \mathrm{deg}$, the longitudinal extension of the measured vortex section was only a few meters.

The total duration of the measurement sequence shown in Fig. 7 was approximately $20 \mathrm{~s}$ for scans 1 and 2 plus 24 s for scans 3 to 6 . In this time, the Falcon was flying approximately $4.6 \mathrm{~km}$ along the vortex pair covering vortex phases from the time of vortex generation $(<10 \mathrm{~s}$ for scan 1$)$ to very weak vortices close to their decay $(\sim 50 \mathrm{~s}$ for scan 6).

Wake-Vortex Parameters Derived From Measured Velocity Profiles

Figure 8 shows the temporal behavior of the wake-vortex heights (the core height of the smoke-seeded port vortex) measured on legs 2-10. These heights were calculated from the measured distances between lidar and vortex core and the nadir angle of the core intersection, taking into account the Falcon attitude (height AGL and roll angle). The vortex age can be exactly estimated, if the track and speed of the Falcon and ATTAS aircraft are known. Because such information was not completely available, we could roughly estimate the vortex age within one scan, that is, within a time interval of $\sim 9.4 \mathrm{~s}$. The observations are covering a period of up to six scans, as in the case of leg 5 (N5). The vortices were generated at the ATTAS flight altitude of $1100 \mathrm{~m}$ AGL and were more or less quickly descending or even reflected by atmospheric shear layers, as in the cases of leg 5 (N5) and leg 7 (N7).

The circulation strengths of the smoke-seeded port vortices measured on legs 2-10 were calculated by integrating the corresponding parts of the velocity envelopes within the interval 3 $6 \mathrm{~m}$ distance from the vortex cores [1,9]. The curves in Fig. 9 show the decay of the vortex strength from $\Gamma_{0}$ (initial circulation measured at the first scan) to half this value after $\sim 50 \mathrm{~s}$. The behavior of the circulation may be explained by the following points:

1) After starting the smoke generator, it takes a while until the smoke is equally distributed in the vortices. That is the reason for larger variations observed in scan 1 and even in scans 2 and 3 .

2) The number of wake-vortex signatures appropriate for estimation of circulation by integration $(3-6 \mathrm{~m})$ of the velocity envelopes is decreasing from nine in scan 1 to two in scan 6 . In the latter case, the difference in circulation by chance is very small. But we have to take into account that the ATTAS vortices are rather small in size as compared with LTA vortices, and that the number of observations is too small for statistical treatment.

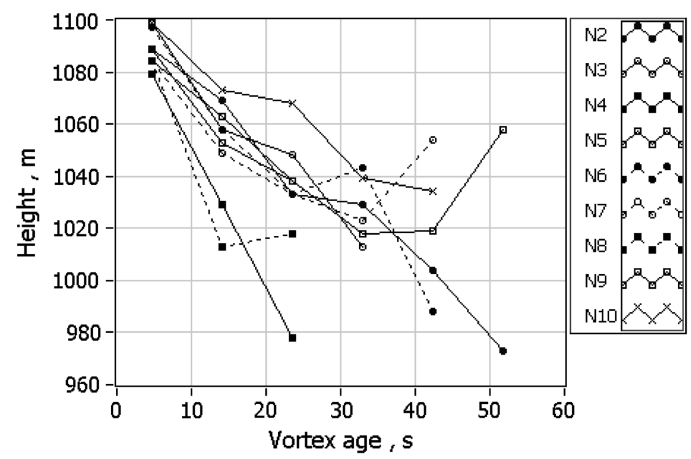

Fig. 8 Height of ATTAS wake-vortex cores measured on legs 2-10.

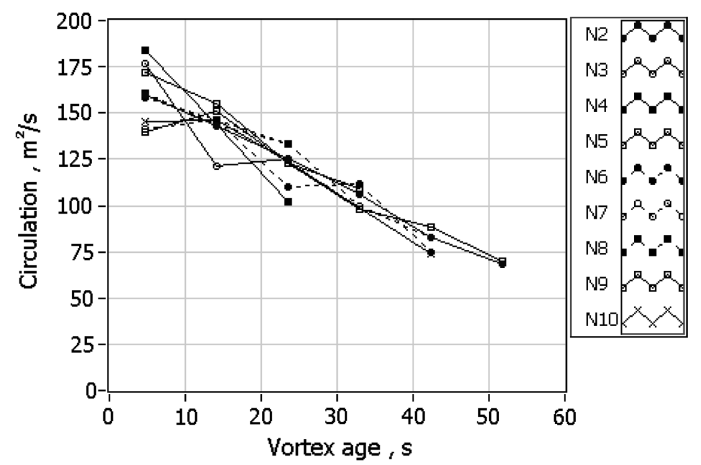

Fig. 9 Circulation of ATTAS wake vortices measured on legs 2-10. 
Table 3 Main parameters for airborne wake-vortex characterization using the pulsed lidar in the Falcon aircraft

\begin{tabular}{|c|c|c|c|}
\hline Vortex characterization & Tryout flights & Flight test 2 & Comments w.r.t F/T-2 \\
\hline Height of vortex generation & $\sim 1000 \mathrm{~m} \mathrm{AGL}$ & $>2000 \mathrm{~m} \mathrm{AGL}$ & Outside ABL \\
\hline Influence of turbulence on WV behavior & Medium & Low & Depending on atomospheric conditions \\
\hline Influence of crosswind on WV tracking & Medium & Low & Adaptation of flight direction required \\
\hline Backscatter, $\mathrm{m}^{-1} \mathrm{sr}^{-1}$ & $\gg 10^{-6}$ & $\gg 10^{-6}$ & Smoke seeding \\
\hline Accumulation $(\mathrm{SNR} \geq 1)$ & 5 shots & 9 shots & \\
\hline No. of LOS radials & $100 / \mathrm{s}$ & $55 / \mathrm{s}$ & \\
\hline Scan lead angle & 35 deg & $\sim 35 \mathrm{deg}$ & \\
\hline Scan speed & $10 \mathrm{deg} / \mathrm{s}$ & $6 \mathrm{deg} / \mathrm{s}$ & \\
\hline Duration of 30 deg scan & $3 \mathrm{~s}$ & $5 \mathrm{~s}$ & Turnback time $>1 \mathrm{~s}$ \\
\hline \multirow[t]{2}{*}{ Spatial resolution at $1000 \mathrm{~m}$ range } & $18 \mathrm{~m}$ & $18 \mathrm{~m}$ & Along LOS radials, between LOS radials \\
\hline & $1.6 \mathrm{~m}$ & $1.7 \mathrm{~m}$ & \\
\hline Accuracy of tang. velocity & $\sim 0.5 \mathrm{~m} / \mathrm{s}$ & $\sim 0.5 \mathrm{~m} / \mathrm{s}$ & \\
\hline Accuracy of core position & $\pm 3 \mathrm{~m}$ & $\sim \pm 3 \mathrm{~m}$ & \\
\hline Accuracy of circulation & $\pm 10 \mathrm{~m}^{2} / \mathrm{s}$ & $\sim \pm 10 \mathrm{~m}^{2} / \mathrm{s}$ & Integration $5-15 \mathrm{~m}$ \\
\hline Flight pattern & Several & 5 loops & Opposite directions \\
\hline Smoke distribution & $10 \times \sim 1 \mathrm{~min}$ & $10 \times 2 \mathrm{~min}$ & Total of $20 \mathrm{~min}$ \\
\hline No. of scans/plume & 10 & 21 & Scan repetition $6 \mathrm{~s}$ \\
\hline Measured velocity profiles & $\sim 60$ & $\sim 210$ & Per flight \\
\hline Duration of flight pattern & $\sim 50 \mathrm{~min}$ & $75-90 \mathrm{~min}$. & Depending on wind \\
\hline
\end{tabular}

\section{System Performance}

The main parameters for airborne WV characterization by means of the pulsed lidar in the Falcon aircraft are listed in Table 3. Column 2 indicates the parameters achieved during the tryout flights. Column 3 indicates the parameters expected for the flight-test no. 2 (F/T-2), where measurement of VW generated by LTA is planned.

\section{Conclusions from Tryout Flights and Implications for Future Tests}

The tryout flights carried out in April 2005 have shown encouraging results which allowed successful airborne measurements of the much larger and stronger vortices generated by LTA to be characterized in future campaigns (in particular, F/T-2). After vortex generation, the initial circulation of the ATTAS aircraft is approximately $150 \mathrm{~m}^{2} / \mathrm{s}$ as compared with, for example, more than $500 \mathrm{~m}^{2} / \mathrm{s}$ for heavy aircraft. The method has been verified on smokeseeded wake vortices, in such favoring both the adjustment of the flight pattern and the achievement of strong SNR for the lidar measurements. The application for unseeded vortices seems feasible, but it needs separate studies and experiments.

Some recommendations and implications for airborne wakevortex characterization are as follows:

1) The measurements should be carried out above the atmospheric boundary layer (2000-3000 m AGL) allowing the observation of long-living vortices only weakly influenced by wind shear and turbulence.

2) By orientation of the flight pattern in the mean wind direction, the influence of the crosswind component can be minimized and the vortex tracking can be facilitated. This necessitates precise wind prediction both in the altitude of vortex location and in the flight altitude of the airborne platform.

3) Before each flight, the exact definition of the flight pattern is required. Thereby, the straight flight legs have to be larger than the pure measurement distance defined by the length of the smoke plume plus a certain distance without smoke to allow exact phasing of both aircraft.

4) During flight, steady communication between both aircraft is required for fine adjustment of the flight tracks. A downward-looking video camera with display in the cockpit would be helpful. Moreover, the vision from aircraft to aircraft/smoke should not be blocked by clouds.

5) The procedure can be controlled by recommendations from the Falcon pilots based on TCAS (traffic collision avoidance system) information by command for turning toward the next leg, respectively, or by command for switching on the smoke generators.

6) The proposed flight and scanning strategy allows the measurement of more than 10 profiles of the velocity envelope at more than 20 positions of the wake. In this way, vortex ages of several minutes can be covered during each overflight. The number of overflights (oval pattern) and the length of each measurement sequence are limited by the available smoke.

7) The possibility of combining two scanning strategies during one measurement sequence can be considered for gaining optimum results.

8) It is recommended to fly the airborne platform (Falcon) $\sim 900 \mathrm{~m}$ above the wake-generating aircraft, so that the mean height difference between the Falcon and the vortices is $\sim 1000 \mathrm{~m}$.

9) The linear scan of \pm 15 deg with a lead angle of 35 deg covers a swath of $\pm 220 \mathrm{~m}$ at a mean distance of $1000 \mathrm{~m}$. This width is wide enough for tracking the vortices with good reliability.

10) The real-time observation of the wake signatures on the quicklook monitor with a repetition rate of several seconds allows one to control and correct the position of the airborne platform.

11) During data processing, the velocity components inferred by the Falcon speed and attitude variations have to be corrected by means of the aircraft data (ARINC database). The contribution of the aircraft speed must be taken into account already for quick-look monitoring during flight. Accurate flight track information of the wake generation aircraft needs to be available for offline final processing.

\section{Acknowledgements}

The modification of the Doppler lidar and the integration in the Falcon aircraft were supported by the Deutsches Zentrum fuer Luftund Raumfahrt (DLR) project "Wirbelschleppe II." The tryout flights were carried out in the framework of the aircraft wing with advanced technology operation (AWIATOR) project (Contract No. G4RD-CT-2002-00836) within the Fifth Research Framework Programme of the European Union.

\section{References}

[1] Köpp, F., Rahm, S., and Smalikho, I. N., "Characterization of Aircraft Wake Vortices by $2-\mu \mathrm{m}$ Pulsed Doppler Lidar," Journal of Atmospheric and Oceanic Technology, Vol. 21, No. 2, 2004, pp. 194-206.

[2] Köpp, F., Rahm, S., Smalikho, I. N., Dolfi, A., Cariou, J.-P., Harris, M., and Young, R. I., "Comparison of Wake-Vortex Parameters Measured by Pulsed and Continuous-Wave Lidars," Journal of Aircraft, Vol. 42, No. 4, 2005, pp. 916-923.

[3] Köpp, F., Rahm, S., and Smalikho, I. N., "Wake-Vortex Raw Data F/T1: DLR Ground-Lidar Measurements," AWIATOR TR D1.1.3-7 (internal), Oct. 2005.

[4] Keane, M., Buckton, D., Redfern, M., Bollig, C., Wedekind, C., Köpp, F., and Berni, F., "Axial Detection of Aircraft Wake Vortices Using Doppler Lidar," Journal of Aircraft, Vol. 39, No. 5, 2002, pp. 850-861. 
[5] Mutuel, L., "I-Wake, Final Publishable Report," IWAKE 5-D-RETHAV-055, June 2006.

[6] Köpp, F., and Smalikho, I. N., "Wake-Vortex Characterisation by Airborne Doppler Lidar: Feasibility Study," DLR Report, March 2004.

[7] Crow, S.C., "Stability Theory for a Pair of Trailing Vortices," AIAA Journal, Vol. 8, No. 12, 1970, pp. 2172-2179.

[8] Gerz, T., Holzäpfel, F., Bryant, W., Köpp, F., Frech, M., Tafferner, A., and Winckelmans, G., "Research Towards a Wake-Vortex Advisory System for Optimal Aircraft Spacing," Comptes Rendus Physique, Académie des Sciences, Paris, Vol. 6, Nos. 4-5, 2005, pp. 501-523.

[9] Holzäpfel, F., Gerz, T., Köpp, F., Stumpf, E., Harris, M., Young, R.I., and Dolfi, A., "Strategies for Circulation Evaluation of Aircraft Wake Vortices Measured by Lidar," Journal of Atmospheric and Oceanic Technology, Vol. 20, No. 8, 2003, pp. 1183-1195. 